\title{
Perioperative stroke Part II: Cardiac surgery and cardiogenic embolic stroke
}

The major mechanism of stroke in cardiac surgery is embolization. The risk is higher in intracardiac than in extracardiac surgery. The incidence of stoke associated with CABG is about 5\%. The cerebral protective properlies of isoflurane and thiopentone, acid-base managemen, and monitoring of cerebral perfusion during cardiopulmonary bypass are discussed. Prophylactic carotid endarlerectomy for patients with asymptomatic carotid disease before cardiac surgery is not necessary. Symptomatic carotid disease increases the risk of stroke, and the management of patients who have both symptomatic coronary and carotid artery diseases is discussed. Cardiogenic embolism is probably responsible for many perioperative strokes. Patients with atrial fibrillation, valvular disease, and prosthetic heart valves are at high risk of cardiogenic embolism. Strokes associated with cardioversion, pacemaker inserrion, coronary arteriography and angioplasty are explored.

La plus importante cause d'apoplexie lors de la chirurgie cardiaque demeure l'embolisation. Le risque est plus grand lorsque la chirurgie est intracardiaque plutôt qu'extracardiaque. L'incidence d'apoplexie associée au pontage aortocoronarien est à peu près $5 \%$. Les propriétés protectrices du cerveau, de l'isoflurane et du thiopentone, la conduite de l'équilibre acido-basique et la surveillance de la perfusion cérébrale durant la circulation extracorporelle sont discutées. L'andartérectomie carotidienne prophylactique pour les patients atteints de maladie carotidienne asymptomatique avant la

\section{Key words}

BRAIN: infarction;

COMPLICATION: stroke, perioperative;

EMBOLISM: cerebral.

From the Department of Anaesthesia, Faculty of Medicine, University of British Columbia, Vancouver, British Columbia. Address correspondence to: Dr. David H.W. Wong, Department of Anaesthesia, Vancouver General Hospital, Room 3200, 910 West 10th Avenue, Vancouver, British Columbia, Canada V5Z 4E3.

Accepted for publication 12th December, 1990. chirurgie cardinque n'est pas nécessaire. Les maladies carotidiennes svmptomatiques augmemtent le risque d' apoplexie, et la conduite à faire chez les patients qui ont une symptomatologie coronarienne et carotidienne est discutée. L'embolisation cardiogénique est probablement responsable de plusieurs épisodes d'apoplexie périopératoire. Les patiems atteints de fibrillation auriculaire, de maladies valvulaires, et ayamt des valves cardiaques prosthétiques sont à risque élevé d'embolisation cardiogénique. Les apoplexies associées à la cardioversion, l'insertion de pace inaker, l'artériographie coronarienne el l'angioplastie sont explorées.

\section{Contents}

Cardiac surgery

- Stroke associated with cardiopulmonary bypass

- Mechanism of intraoperative neurological injury

- Surgical factors

- Cardiopulmonary bypass

- Intraoperative management

- Protective effect of anaesthetic agents

- Hypothermia, haemodilution and acid-base management

- Cerebral perfusion

- Monitoring of cerebral perfusion

- Cardiac surgicat patients with carotid artery disease

- Asymptomatic bruit or carotid stenosis

- Symptomatic carotid artery disease

Perioperative cardiogenic embolic stroke

- Cardiac diseases

- Atrial fibrillation

- Valvular heart disease

- Prosthetic heart valves

- Perioperative management of patients on long-term anticoagulant therapy

- Perioperative prophylactic antibiotic therapy

- Patent foramen ovale and ventricular septal defect

- Diagnostlc and therapeutic procedures

- Direct curtent cardioversion

- Pacemaker insertion

- Coronary arteriography and coronary angioplasty 


\section{Cardiac surgery}

Stroke associated with cardiopulmonary bypass

The incidence of neurological injury in patients undergoing cardiac surgery varies with the methods of evaluation. These may be based on clinical examination, neuropsychological testing, biochemical variables or EEG. The incidence of abnormalities tends to be underestimated in retrospective chart reviews, ' and in studies performed by non-neurologists. ${ }^{2}$

Because of an increased risk of embolization, neurological complications are more frequent following intracardiac surgery such as valve replacement than following extracardiac procedures such as coronary artery bypass. Earlier studies reported persistent neurological deficits in more than $15 \%$ of patients following intracardiac surgery. ${ }^{3-5}$ In a survey of 1689 consecutive patients who underwent isolated aortic valve replacement at the Cleveland Clinic Foundation from 1972 through 1989, stroke occurred in 29 patients $(1.7 \%) .^{6}$ In 1980 Sotaniemi's prospective study of 100 patients undergoing valve replacement surgery showed a $37 \%$ incidence of postoperative deficit, but only $7 \%$ had a persistent severe deficit. $^{\text {? }}$

Most retrospective studies of coronary artery bypass surgery show a low neurological complication rate. Lee et al. reported an occurrence of cerebral infarction in $0.7 \%$ of 943 patients. $^{8}$ In Gonzaalez-Scarano and Hurtig's series of 1427 patients, there were 19 (1.3\%) who developed postoperative neurological complications. ${ }^{9}$ Martin and Hashimoto reported postoperative stroke in eight patients among $253(3.7 \%) .^{10}$ In a series of 3206 patients reported by Bojar et al., there were $32(1 \%)$ who developed major neurological deficits. " Coffey et al. reported 63 of 1669 patients (3.8\%) developed postoperative neurological complications such as altered mental state, stroke or seizure. ${ }^{12}$ On the other hand, prospective studies revealed a higher incidence of stroke. In the prospective study of Shaw et al. neurological complications occurred in 191 of their 312 patients $(61 \%)$, and 15 patients $(4.8 \%)$ suffered a stroke. ${ }^{13}$ Similarly, Breuer et al.'s prospective study or 421 patients revealed $22(5.2 \%)$ postoperative strokes. ${ }^{14}$ Thus the current incidence of perioperative stroke associated with cardiac surgery is about 5\% (Table I).

Following cardiac transplantation, 50 to $60 \%$ of patients developed neurological complications. ${ }^{15,16}$ Cerebral infarcts were present in $20 \%$ of cases in autopsy series and in 13 to $15 \%$ in clinical series, ${ }^{15,17}$ and were primarily due to embolism. Intracerebral haemorrhage occurred in $5 \%$ of early transplants, and were probably due to relative cerebral hyperperfusion from abrupt increases in blood pressure and cerebral blood flow in the presence of a disordered cerebral autoregulatory response. ${ }^{18}$

\section{Mechanism of intraoperative neurological injury}

Neurological damage may result from inadequate cerebral perfusion or embolization. The primary mechanism causing focal ischaemia and infarction associated with cardiac surgery is embolization.

\section{SURGICAL FACTORS}

Gaseous or particulate emboli may be introduced into the arterial circulation during surgery, especially when the heart or aorta are opened. Embolic phenomena are more common in intracardiac surgery than in closed cardiac procedures. ${ }^{19}$ Gaseous microemboli can be detected in the majority of cases by using an ultrasonic microbubble detector ${ }^{20}$ or oesophageal M-mode echocardiography. ${ }^{21}$ Surgical manoeuvres such as detection and removal of intracardiac air, filling the heart with fluid before unclamping the aorta greatly reduces gaseous microembolism. ${ }^{22-25}$ Lowering the head ${ }^{26}$ and digital compression of the carotid arteries ${ }^{27}$ may prevent emboli from entering the cerebral circulation when the heart begins to eject at the time of coming off cardiopulmonary bypass. Avoidance of nitrous oxide may help to minimize the potential exacerbation of neurological injury. ${ }^{28}$

Calcification and atheroma of the ascending aorta ${ }^{29,30}$ and thrombi in the left ventricle ${ }^{31}$ are important sources of emboli. It has been suggested that, in patients with severe calcific disease of the aorta, femoral artery cannulation is preferable to aortic cannulation to avoid aortic manipulation. ${ }^{32}$

\section{CARDIOPULMONARY BYPASS}

Cardiopulmonary bypass (CPB) may introduce a wide variety of material, including air, fat, antifoaming agents, plastic chips, leukocytes, platelets and fibrin aggregates,

TABLE I Perioperative stroke in CABC

\begin{tabular}{|c|c|c|}
\hline Author & No. patients & $\begin{array}{l}\text { Perioperative } \\
\text { stroke }\end{array}$ \\
\hline \multicolumn{3}{|l|}{ Retrospective studies } \\
\hline Lee et al..$^{8}$ & 943 & $0.7 \%$ \\
\hline Gonzaalez-Scarano et al. ${ }^{9}$ & 1,427 & $1.3 \%$ \\
\hline Martin et al. ${ }^{10}$ & 253 & $3.7 \%$ \\
\hline Bojar et al." & 3,206 & $1.0 \%$ \\
\hline Coffey el al..$^{12}$ & 1,669 & $3.8 \% *$ \\
\hline \multicolumn{3}{|l|}{ Prospective studies } \\
\hline Shaw et al. ${ }^{13}$ & 312 & $4.8 \%$ \\
\hline Breuer el al. ${ }^{14}$ & 421 & $5.2 \%$ \\
\hline
\end{tabular}

*Included altered mental state, stroke and seizure. 
TABLE II Effects of isoflurane on cerebral perfusion and metabolism

\begin{tabular}{|c|c|c|c|}
\hline Author & \multicolumn{3}{|c|}{ Effect of isoflurane } \\
\hline Newberg \& Michenfelder $(1983)^{48}$ & \multicolumn{3}{|c|}{$\begin{array}{l}\text { Hypoxemic mice: } \uparrow \text { survival time. Haemorrhagic hypolension in dogs: } \\
\text { preserved energy stores better than } \mathrm{N}_{2} \mathrm{O} \text {. }\end{array}$} \\
\hline Todd \& Drummond $(1984)^{49}$ & \multicolumn{3}{|c|}{$\begin{array}{l}\text { Normocarbic cals: no significant changes in } \mathrm{CBF} \text {, greater } \downarrow \mathrm{CMRO}_{2} \text {, } \\
\text { and less impairment of autoregulation, compared to halothane. }\end{array}$} \\
\hline Baughman et al. $(1988)^{50}$ & \multicolumn{3}{|c|}{$\begin{array}{l}\text { Incomplete cerebral ischaemia in rals: provided beller neurological and } \\
\text { histological outcomes, compared to } \mathrm{N}_{2} \mathrm{O} \text {. }\end{array}$} \\
\hline Newberg et al. $(1983)^{51}$ & \multicolumn{3}{|c|}{$\begin{array}{l}\text { Dogs: dose-related } \downarrow \mathrm{CMRO}_{2} \text { unlil isoeleclric EEG at } 3 \% \text { end-tidal } \\
\text { concentration, with preservation of brain energy state. }\end{array}$} \\
\hline Nehls et al. $(1987)^{52}$ & \multicolumn{3}{|c|}{ Focal ischaemia in baboons: no protection, compared to thiopentone. } \\
\hline Young et al. $(1989)^{53}$ & \multicolumn{3}{|c|}{$\begin{array}{l}\text { Carotid endarterectomy: } \mathrm{CBF} \text { less, but } \mathrm{CMRO}_{2} \text { was the same, } \\
\text { compared to halothane. }\end{array}$} \\
\hline Newberg et al. $(1984)^{54}$ & \multicolumn{3}{|c|}{$\begin{array}{l}\text { Isollurane-induced hypotension in dogs: } \downarrow \mathrm{CMRO}_{2}, \downarrow \mathrm{CBF} \text {, normal } \\
\text { aerobic metabolism. }\end{array}$} \\
\hline Newman et al. $(1986)^{55}$ & \multicolumn{3}{|c|}{$\begin{array}{l}\text { Isoflurane-induced hypotension during cerebral aneurysm clipping: } \\
\leftrightarrow \text { CBF, } \downarrow \mathrm{CMRO}_{2} \text {. }\end{array}$} \\
\hline Artru $(1986)^{56}$ & \multicolumn{3}{|c|}{$\begin{array}{l}\text { lsoflurane-induced hypotension during hypocapnia in dogs: no adverse } \\
\text { effect on cerebral metabolism and EEG. }\end{array}$} \\
\hline Mutch et al. $(1989)^{57}$ & \multicolumn{3}{|c|}{$\begin{array}{l}\text { Phenylephrine treatment for haemorrhagic hypotension during } \\
\text { isoflurane anaesthesia in rats: no cerebral vasoconstriction, tolal and } \\
\text { rCBF mainlained. }\end{array}$} \\
\hline Ruta et al. $(1989)^{38}$ & \multicolumn{3}{|c|}{$\begin{array}{l}\text { Isoflurane-induced hypotension in rabbits: rCBF supratentorial }< \\
\text { infiratentorial. Treatment methods to support BP in presence of } \\
\text { hacmorrhage differed in effects on rCBF. }\end{array}$} \\
\hline Messick el al. $(1987)^{59}$ & \multicolumn{3}{|c|}{$\begin{array}{l}\text { Carotid endarterectomy: critical } \mathrm{rCBF}<10 \mathrm{ml} \cdot 100 \mathrm{~g}^{-1} \cdot \mathrm{min}^{-1} \text {, much } \\
\text { lower than that previous reported for halothane. }\end{array}$} \\
\hline \multirow[t]{4}{*}{ Michenfelder et al. $(1987)^{60}$} & \multicolumn{3}{|c|}{ Carotid endarterectomy, retrospective: } \\
\hline & & Critical $C B F$ & $E E G$ ischaemic change \\
\hline & $\begin{array}{l}\text { Isoflurane } \\
\text { Enflurane } \\
\text { Halothane }\end{array}$ & $\begin{array}{l}10 \mathrm{ml} \cdot 100 \mathrm{~g}^{-1} \cdot \min ^{-1} \\
15 \mathrm{ml} \cdot 100 \mathrm{~g}^{-1} \cdot \min ^{-1} \\
20 \mathrm{ml} \cdot 100 \mathrm{~g}^{-1} \cdot \mathrm{min}^{-1}\end{array}$ & $\begin{array}{l}18 \% \\
26 \% \\
25 \%\end{array}$ \\
\hline & \multicolumn{3}{|c|}{$\begin{array}{l}\text { No difference in neurological outcome, as shunt was inserted based on } \\
\text { EEG changes. }\end{array}$} \\
\hline Woodcock el al. $(1987)^{61}$ & \multicolumn{3}{|c|}{$\begin{array}{l}\text { Thiopental } \rightarrow \downarrow \mathrm{CMRO}_{2} \& \downarrow \mathrm{CBF} \\
\text { Isoflurane } \rightarrow \downarrow \mathrm{CMRO}_{2} \& \leftrightarrow \mathrm{CBF}\end{array}$} \\
\hline
\end{tabular}

into the systemic circulation. ${ }^{33-35}$ Membrane oxygenators produce fewer microemboli than bubble oxyyenators. ${ }^{36-38}$ Proper priming procedures can reduce foreign particles from entering the system. ${ }^{34}$ Adequate anticoagulation, maintaining the activated clotting time greater than 400 $\mathrm{sec}$, is essential in reducing fibrin and platelet aggregation. ${ }^{39}$ Arterial filters ${ }^{37.40-42}$ and filtration of the cardiotomy suction retums ${ }^{43.44}$ are effective in removing both solid and gaseous microparticles and reducing the number of microemboli delivered to the arterial circulation. Some studies have shown that filters are effective in reducing the incidence or severity of neurological injury following CPB. ${ }^{45-47}$

\section{Intraoperative management}

PROTECTIVE EFFECT OF ANAESTHETIC AGENTS

Many animal and clinical studies have attempted to examine if isoflurane provides cerebral protection against ischaemia (Table II). 
Newberg and Michenfelder reported that the survival time of severely hypoxaemic mice was increased when they were exposed to $1.0 \%$ and $1.4 \%$ isoflurane. ${ }^{48}$ In normocarbic mechanically ventilated cats, isoflurane at $0.5,1.0$ and $1.5 \mathrm{MAC}$, caused no changes in $\mathrm{CBF}$, greater decreases in $\mathrm{CMRO}_{2}$, and less impairment of autoregulation than comparable MACs of halothane. ${ }^{49}$ Baughman et al. found that, in rats with incomplete cerebral ischaemia produced by carotid artery occlusion, combined with haemorrhagic hypotension, isoflurane and halothane both provided better neurological and histological outcomes than $\mathrm{N}_{2} \mathrm{O}$ controls. ${ }^{50}$ In dogs, a dose-related decrease in cerebral oxygen consumption $\left(\mathrm{CMRO}_{2}\right)$ was evident until the onset of isoelectric EEG, which occurred at an isoflurane end-expired concentration of $3 \%$. Further increases of the isoflurane concentration did not produce any more reduction of the $\mathrm{CMRO}_{2}$. The normal concentrations of ATP and phosphocreatine in the brain biopsies suggested that this concentration of isoflurane had no direct toxic effect on the cerebral metabolic pathways. ${ }^{51}$ Nehls et al., however, in a focal ischaemia model using transorbital middle cerebral artery occlusion in baboons, could not demonstrate any protective value of isoflurane in concentrations sufficient to maintain burst suppression on the EEG, when compared with thiopental. ${ }^{52}$ One possible explanation for the apparent negative effects was that isoflurane, in contrast to the cerebral vasoconstricting properties of thiopentone, was a mild cerebral vasodilator and could cause an unfavourable redistribution of blood flow during regional ischaemia. Furthermore, Young et al. showed that although the CBF was greater during halothane than during isoflurane or fentanyl anaesthesia in patients undergoing carotid endarterectomy, there was no demonstrable difference in the $\mathrm{CMRO}_{2}$ between the three anaesthetic agents. ${ }^{53}$

The cerebral effects of isoflurane during hypotension have also been studied. The cerebral energy stores of ATP and phosphocreatine, and the cerebral energy charge in dogs, during a nine-minute haemorrhagic hypotension to $30 \mathrm{mmHg}$, were sustained at much higher levels when exposed to $3 \%$ isoflurane than $\mathrm{N}_{2} \mathrm{O}$ controls. ${ }^{48}$ Normal aerobic metabolism was preserved in association with decreases in both the $\mathrm{CBF}$ and the $\mathrm{CMRO}_{2}$ during isoflurane-induced hypotension in dogs. ${ }^{54}$ During isoflurane-induced hypotension to a mean arterial pressure of $50 \mathrm{mmHg}$ in patients undergoing craniotomy for clipping of cerebral aneurysms, Newman et al. found that the $\mathrm{CMRO}_{2}$ was reduced while the mean CBF remained relatively unchanged, indicating that the global oxygen supply-demand balance was favourably influenced by isoflurane. ${ }^{55}$ Artru found no adverse effect on cerebral metabolism and the EEG during hypocapnia (to $\mathrm{PaCO}_{2}$ of
$20 \mathrm{mmHg}$ ) plus isoflurane-induced hypotension (cerebral perfusion pressure to as low as $40 \mathrm{mmHg}$ for 30 minutes) in dogs. ${ }^{56}$ Mutch $e t$ al. showed that during isoflurane anaesthesia (at inspired 1.5 MAC) in rats subjected to haemorrhagic hypotension, phenylephrine infusion did not cause cerebral vasoconstriction and effectively maintained both total and regional CBF. ${ }^{57}$ Ruta and Mutch found that, in rabbits, isoflurane-induced hypotension to a mean arterial pressure (MAP) of $50 \mathrm{mmHg}$ (the lower limit of the autoregulatory range) produced regional differences in cerebral perfusion, with decreased rCBF to the supratentorial structures, increased $\mathrm{rCBF}$ to the cerebellum and the brain stem, and unchanged total $C B F$ (tCBF). The rCBF to all regions of the brain became pressure passive, as expected, when MAP was further decreased to $30 \mathrm{mmHg}$ by haemorrhage. Raising the MAP back to $50 \mathrm{mmHg}$ by a reduction of the inspired isoflurane concentration, restoration of blood volume, or infusion of phenylephrine was effective in improving the ICBF and the rCBF to the supratentorial structures. However, reduction of the inspired isoflurane concentration did not improve the rCBF to the posterior fossa structures. Nevertheless, the $\mathrm{rCBF}$ to these struclures at this time was not different from that before hypotension was induced with isoflurane. The $\mathrm{rCBF}$ autoregulation curve was shifted downward and to the right in the infratentorial structures. ${ }^{58}$

Messick et al., in a study on isoflurane anaesthesia for carotid endarterectomy, found that the level of rCBF below which EEG signs of ischaemia occurred (critical rCBF) was $<10 \mathrm{ml} \cdot 100 \mathrm{~g}^{-1} \cdot \mathrm{min}^{-1}$, much lower than that previously reported for halothane $\left(18-20 \mathrm{ml} \cdot 100 \mathrm{~g}^{-1}\right.$. $\left.\min ^{-1}\right) .{ }^{59}$ This lower value of critical rCBF for isoflurane was also found by Michenfelder et al. in their retrospective review of 2010 carotid endarterectomies in which both EEG and CBF were measured. ${ }^{60}$

It appears that isoflurane is the preferred volatile anaesthetic for protection against cerebral ischaemia. The mechanism of cerebral protection is similar to that of the barbiturates, and is mainly by a reduction in $\mathrm{CMRO}_{2}$ through a depression of synaptic transmission. The reduction in $\mathrm{CMRO}_{2}$ is maximum when the $\mathrm{EEG}$ becomes isoelectric. A high inspiratory concentration of isoflurane ( 2.5 to $3.5 \%$ ) is required to induce EEG burst suppression. Woodcock et al. compared the cerebral haemodynamic and metabolic effects of isoflurane and thiopentone EEG suppression during CPB. The thiopentone-induced EEG suppression was associated with a reduction of both the $\mathrm{CMRO}_{2}$ and the CBF. However, although isofluraneinduced EEG suppression reduced the $\mathrm{CMRO}_{2}$, it was not associated with a reduction of $\mathrm{CBF}^{61}$ The authors suggested that the thiopentone-induced reduction in $\mathrm{CBF}$ 
would produce a proportionate reduction in the delivery of emboli to the cerebral circulation. In addition, the cerebral vasoconstrictive properties of thiopentone may induce a more favourable redistribution of CBF towards an ischaemic focus.

Isoflurane may produce myocardial ischaemia by inducing coronary steal. The studies by Slogoff el $\mathrm{al}$. and Tuman et al., however, did not show deleterious effects of isoflurane in CABG. ${ }^{62,63}$ On the other hand, Inoue et al. showed that isoflurane produced significantly worse outcomes than enflurane when used in CABG, with higher postoperative myocardial infarction $(4.0 \%$ vs $1.8 \%$ ) and higher in-hospital deaths $(2.1 \%$ vs $0.3 \%)$. Cardioplegic solutions were not used for myocardial protection, and the volatile agent was used as the primary anaesthetic during CPB in this series. ${ }^{64}$

Barbiturates in high doses suppress neuronal electrical activity and reduce cerebral metabolic demands. The reduction of cerebral metabolism is maximal when the EEG becomes isoelectric, at which level the membrane ion pumps remain intact. ${ }^{65-67}$ Barbiturates, in sufficient dosage to cause electrical silence in nonischaemic brain, may divert flow to ischaemic areas. ${ }^{68}$ However, to provide cerebral protection, they must be given either before or soon after an insult, and the protection is effective in temporary, rather than permanent, focal ischaemia ${ }^{69}$ Nussmeier et al., in a prospective randomized study of open-ventricle operations requiring CPB, found that thiopentone, given in sufficient doses to maintain electroencephalographic silence for the duration of bypass, reduced the neuropsychiatric dysfunction of cerebral embolism associated with open heart operations. The neuropsychiatric dysfunction, which included hemiparesis, homonymous hemianopsia, dysarthria, disorientation, memory loss, excessive lethargy, hallucinations, delusions and hostility, occurred in $5.6 \%$ of 89 patients treated with thiopentone, and in $8.6 \%$ of 93 patients not treated. By the tenth postoperative day, all neuropsychiatric abnormalities disappeared in the thiopentonetreated patients, but persisted in $7.5 \%$ of patients in the untreated group. ${ }^{70}$ The authors recommended this therapy for patients undergoing valve replacement, resection of ventricular aneurysms, and other operations requiring opening of the ventricle. However, barbiturates in such doses may create additional problems of cardiovascular instability and prolonged emergence from anaesthesia.

\section{HYPOTHERMIA, HAEMODILUTION AND ACID-BASE MANAGEMENT}

Mild hypothermia $\left(28\right.$ to $30^{\circ} \mathrm{C}$ ) and haemodilution (20 to $30 \%$ ) are used routinely during CPB. Hypothermia reduces cerebral requirements for oxygen and glucose and, theoretically, may confer protection in cerebral ischaemia. ${ }^{71,72}$ As hypothermia increases blood viscosity, haemodilution is used during bypass to minimize driving pressures required to maintain flow. ${ }^{73}$

While we generally agree that the normal arterial $\mathrm{pH}$ and $\mathrm{PCO}_{2}$ values at $37^{\circ} \mathrm{C}$ are 7.4 and $40 \mathrm{mmHg}$ respectively, the values at lower body temperatures that we consider to be ideal are not clear. The solubility of $\mathrm{CO}_{2}$ in blood increases as temperature decreases, such that $\mathrm{PCO}_{2}$ decreases and $\mathrm{pH}$ increases. Results from blood gas analysis corrected to the patient's temperature will indicate respiratory alkalosis. Whether we should use values temperature-corrected to actual body temperature or uncorrected at the measuring electrode's temperature is controversial.

Some believe that it is desirable to maintain a normal acid-base relationship, and adjust the $\mathrm{pH}$ to 7.4 , and $\mathrm{PCO}_{2}$ to $40 \mathrm{mmHg}$, irrespective of the temperature. ${ }^{74}$ This is the "pH-stat" approach. It is often necessary to add $\mathrm{CO}_{2}$ to the oxygenator to achieve these values during hypothermic CPB. These values would correspond to hypercapnia and acidosis at the electrode temperature. The temperature chosen for correction is inconsistent, and may be nasopharyngeal, oesophageal, tympanic, bladder or that of the perfusate. Over- or under-correction often results as temperature gradients exist between tissues during cooling and rewarming.

Cold-blooded animals behave quite differently from this in a cold environment. As their body temperature falls, their arterial $\mathrm{PCO}_{2}$ decreases and $\mathrm{pH}$ increases, and the content of $\mathrm{CO}_{2}$ remains constant. The $\mathrm{pH}$ of their arterial blood is maintained at 7.4 when measured with a $37^{\circ} \mathrm{C}$ electrode without temperature correction. The charge state of the imidazole radical of histidine (the alpha charge), upon which many enzymatic and transport activities are dependent, is influenced by the arterial $\mathrm{PCO}_{2}$. Maintenance of a constant alpha charge allows the cold-blooded animal to survive at low temperatures in an active state. ${ }^{75}$ The "alpha-stat" approach imitates the cold-blooded animals, maintaining uncorrected values at normal ranges. As the $\mathrm{pH}$ of neutrality (where $\mathrm{H}^{+}=$ $\mathrm{OH}^{-}$) increases when temperature decreases, this approach maintains electrochemical neutrality.

McConnell et al. showed that, in dogs undergoing hypothermic CPB at $28^{\circ} \mathrm{C}$, an increase of the arterial $\mathrm{pH}$ from 7.40 to 7.70 produced an increase in coronary blood flow and myocardial lactate utilization with an improvement of the left ventricular performance. ${ }^{76} \mathrm{Ohmura}$ et al. found that, in dogs subjected to surface-induced hypothermia to $24^{\circ} \mathrm{C}$, maintaining normocarbia by the addition of $\mathrm{CO}_{2}$ caused a rapid decrease in the cardiac index and an increase in both pulmonary and systemic 
vascular resistances. ${ }^{77}$ The alpha-stat approach thus appears to be more beneficial to the cardiovascular system than the pH-stat approach.

However, the cerebral circulation is a concern here. Since both hypothermia and low $\mathrm{PCO}_{2}$ decrease CBF, cerebral ischaemia is a potential problem with the alpha-stat approach. Differences in the anaesthetic techniques and the methods of $\mathrm{CBF}$ measurements resulted in conflicting data regarding the effect of $\mathrm{CO}_{2}$ on $\mathrm{CBF}$ during hypothermic CPB. Henriksen et al. reported that, in patients anaesthetized with enflurane during the prebypass period, hypothermic CPB was associated with an increase in $\mathrm{CBF}$ and impairment of $\mathrm{CO}_{2}$ responsiveness. ${ }^{78}$ Govier et al., on the other hand, using diazepam and fentanyl, found that $\mathrm{CBF}$ decreased during hypothermic $\mathrm{CPB}$, and the responsiveness of the CBF to changes in $\mathrm{PaCO}_{2}$ was maintained. ${ }^{79}$ Prough et al. also found that $\mathrm{CBF}$ remained responsive to changes in $\mathrm{PaCO}_{2}$ during hypothermic, nonpulsatile $\mathrm{CPB}$ in patients anaesthetized with high-dose fentanyl. ${ }^{80} \mathrm{Hägerdal}$ et al. found that, in rats, although the $\mathrm{CBF}$ decreased with decreasing $\mathrm{PaCO}_{2}$ during hypothermia, there was no evidence of tissue hypoxia, as the $\mathrm{CMRO}_{2}$ decreased with hypothermia. ${ }^{81}$ Murkin et al. found that, during hypothermic CPB in patients anaesthetized with fentanyl and diazepam, the cerebral metabolic rate for oxygen $\left(\mathrm{CMRO}_{2}\right)$ was reduced. In patients managed with the $\mathrm{pH}$-stat approach (temperature-corrected), the CBF was higher, and was independent of $\mathrm{CMRO}_{2}$, but correlated with cerebral perfusion pressure (CPP). This led to hyperperfusion relative to the cerebral oxygen demand. On the other hand, in patients managed with the alpha-stat approach (non-temperature-corrected), the CBF was lower, and correlated well with $\mathrm{CMRO}_{2}$, but not with CPP. ${ }^{82}$ The fact that most centres use temperature-corrected $\mathrm{CO}_{2}$ for acid-base management suggests that the particular method of acid-base management may not be crucial. ${ }^{82}$ However, any unnecessary increase in CBF may increase the delivery of micro-emboli to the cerebral circulation. Furthermore, unnecessary elevations of $\mathrm{PaCO}_{2}$ may lead to intracerebral steal phenomenon in patients with cerebrovascular disease. It remains to be seen if clinical data can substantiate these theoretical concerns.

\section{CEREBRAL PERFUSION}

Pulsatile perfusion techniques offer theoretical advantages such as better distribution of myocardial perfusion, capillary perfusion, urine output, and preservation of normal pituitary-adrenal stress-response. ${ }^{83-91}$ However, they have the disadvantage of creating increased turbulence of blood flow and thus increased haemolysis. No study has yet shown that pulsatile perfusion can improve neurological outcome in cardiac surgery. The safety and simplicity of the nonocclusive roller nonpulsatile pump make it the most widely used system.

The limits of hypotension that can be tolerated during CPB without neurological injury have not been precisely defined. While early studies showed an increased incidence of neurological damage when the mean arterial pressure decreased below $50 \mathrm{mmHg},{ }^{5,92-95}$ the association has not been confirmed subsequently., 7,9,19,96 It appears that, when alpha-stat acid-base management is used, cerebral perfusion is well maintained at a decreased systemic flow and pressure during CPB. ${ }^{79,80,82}$ Nevertheless, maintenance of adequate flow and pressure can minimize the autoregulatory cerebral vasodilatation associated with marginal cerebral perfusion pressures. Following an unavoidable hypotensive episode, an even higher cerebral perfusion pressure is required to overcome the no-reflow phenomenon. ${ }^{94,97-100}$

\section{MONITORING OF CEREBRAL PERFUSION}

Since perioperative stroke occurs in about $5 \%$ of patients undergoing $\mathrm{CABG}$ and $\mathrm{CPB}$, monitoring techniques capable of early detection of potentially reversible problems would be most useful. The EEG has helped to identify inadequate cerebral perfusion during carotid surgery, and it is logical to extend its use in cardiac surgery.

Witoszka et al., in a retrospective study, found no relationship between the intraoperative EEG abnormalities and the outcome of a selected group of patients (consisting of five intraoperative deaths, 45 postoperative deaths, and 50 survivors) who had cardiac surgery and $\mathrm{CPB}$. They concluded that localizing neurological deficits were likely related to embolism, and were not detectable by the EEG. ${ }^{101}$ Salemo $e t a l$., in a prospective study of the value of EEG monitoring during CABG and valve replacement in 118 patients, found EEG abnormalities in 22 patients ( $18.6 \%$ ). Most of these were transient, but five patients showed severe EEG suppression, which led to the correction of technical problems and subsequent return of normal EEG, and no neurological damage. However, two patients who had normal intraoperative EEG developed postoperative cerebral infarction. They had severe calcific aortic stenosis. The deficit was either missed by the EEG, or developed postoperatively. ${ }^{102}$

Computer-processed EEG monitors can make the interpretation much easier than with conventional EEG. Many models have been evaluated for use during cardiac surgery and CPB. In 1973, Schwartz et al. compared retrospectively the neurological outcome of 100 patients undergoing cardiac surgery, with the information obtained from the Cerebral Function Monitor (CFM, Devices Ltd.), which produced a filtered and compressed EEG signal as a single trace from a pair of parietal 
electrodes. It was possible to predict correctly the neurological outcome in $83 \%$ of the patients by simple quantification of the CFM trace alone. ${ }^{103}$ The Cerebral Function Analysing Monitor (CFAM), which analyzed both the amplitude and the frequency of the EEG as recorded from biparietal electrodes, was evaluated by Nevin et al. in a prospective study on 65 patients undergoing $\mathrm{CABG}$. Unexplained acute changes in both amplitude and frequency distribution (such as sudden reduction in amplitude and frequency, or opening up of the amplitude envelope together with slowing) lasting more than three minutes were considered to be significant CFAM changes. These occurred at various times throughout the operation, although mostly at the beginning of bypass. All patients with two or more CFAM changes during the course of their operation were found to have significant postoperative neuropsychometric deficits. However, $21 \%$ false positive results were seen. ${ }^{104}$ El-Fiki and Fish reported the detection of two ischaemic episodes in a patient undergoing myomectomy for idiopathic hypertrophic subaortic stenosis, using a two-channel Cerebro Trac 2500 EEG Monitor (SRD, Peekskill, NY) which displayed the power/frequency spectrum in DSA and spectral edge frequency set at $95 \%$. An accidental pump disconnection led to an almost total loss of the EEG activity within ten seconds. The EEG recovered in four minutes after perfusion was restored. Air embolization occurred during manipulation of the heart to remove air from the left ventricle. This was associated with severe and prolonged EEG changes. Thiopental infusion was given for protection. The patient recovered with only minimal neurological deficits. ${ }^{105}$ Jones and Scheller reported a case of unexpected interruption in CPB which resulted in profound EEG changes easily detected with a Lifescan processed EEG monitor (Neurometrics, San Diego, $C A$ ) in a patient undergoing mitral valve replacement and CABG. The change in the EEG spectral edge $(95 \%)$ was easily seen, and returned to normal when perfusion was restored. ${ }^{106}$

The EEG is used to provide warning of decreases in the cerebral perfusion to marginal levels as evidenced by a decrease in the frequency and amplitude of electrical activity. However, EEG changes are commonly seen at the onset of CPB. ${ }^{104,105}$ Slowing of the EEG may also be caused by hypothermia ${ }^{107}$ or high-dose narcotic anaesthesia, ${ }^{108,109}$ both of which are commonly used in cardiac surgery. In addition, roller-pumps often produce EEG artifacts. ${ }^{110}$ The development of permanent neurological damage depends on both the severity and the duration of ischaemia, and therefore not all ischaemic EEG changes are associated with postoperative morbidity. Furthermore, strokes caused by small emboli may not be detected by EEG monitoring. For these reasons, routine use of
EEG monitoring during cardiac surgery has not been shown to reduce neurological morbidity, except in the presence of unexpected events. ${ }^{105,106}$ On the other hand, the EEG may be useful in detecting unexpected cerebral hypoperfusion in patients with cerebrovascular disease. ${ }^{111}$ However, von Reutern et al., using transcranial Doppler ultrasonography, could not demonstrate any significant reduction of blood flow in the middle cerebral artery on the side of a severe $(>80 \%)$ carotid obstruction during CPB. The authors concluded that carotid obstruction could not be considered a significant risk factor for the development of intraoperative stroke. ${ }^{112}$

\section{Cardiac surgical patients with carotid artery disease} The natural histories of carotid and coronary artery atherosclerosis are closely related. Indeed, transient ischaemic attacks should be looked upon as a warning for cardiac as well as cerebrovascular disease. ${ }^{113}$ The risk of stroke associated with coronary artery revascularization is increased in patients with symptomatic carotid artery disease. ${ }^{1 / 4}$ On the other hand, myocardial infarction is a major cause of morbidity and mortality associated with carotid endarterectomy. $115-118$

\section{ASYMPTOMATIC BRUIT OR CAROTID STENOSIS}

Central nervous system complications are more common and more severe after CABG surgery than after peripheral vascular surgery. ${ }^{119}$ Does the presence of asymptomatic bruit or asymptomatic carotid stenosis increase the risk of perioperative stroke during cardiac surgery using CPB?

Reed and associates compared 54 patients who developed stroke or transient ischaemic attacks following coronary artery bypass surgery, with 54 randomly selected patients who also had the same operation but had no neurological complications. The number of patients with bruits was small. Nonetheless, their analysis showed that the presence of a preoperative carotid bruit increased the risk of stroke or TIAs by a factor of 3.9. Their study was not specifically directed to asymptomatic bruits, and the postoperative deficits observed were not necessarily related to the side of carotid bruit. ${ }^{20}$

Since cervical bruits are not exclusively due to carotid artery disease, noninvasive evaluation of the carotid system should be performed. Using OPG or Doppler techniques, haemodynamically important carotid stenosis can be found in about $20 \%$ of patients with asymptomatic bruits. ${ }^{121-123}$ Barnes et al. found no significant difference in the perioperative stroke rate between patients with Doppler-documented significant carotid obstruction (2.5\%) and those who had normal or minor lesions in the carotid arteries $(1.8 \%){ }^{122}$ Ivey et al., in their study of 1433 patients undergoing $\mathrm{CPB}$, found no case of stroke in the 82 patients who had asymptomatic bruits, 66 of which 
TABLE III Perioperative stroke in the territory of significant asymptomatic carotid stenosis in CABG

\begin{tabular}{lll}
\hline authors & Diagnosis based on & Perioperative stroke \\
\hline Barnes et al. ${ }^{122}$ & Doppler & $2.5 \%$ of $40 \mathrm{pl}$ with obstruction \\
& & $1.8 \%$ of $284 \mathrm{pt}$ without obstruction \\
Ivey et al. ${ }^{124}$ & Ultrasonic duplex scan & $0 \%$ of $66 \mathrm{pts}$ with $>50 \%$ stenosis \\
Furlan et al. ${ }^{125}$ & Angiography & $1.1 \%$ of $90 \mathrm{pt}$ with $50-90 \%$ stenusis \\
& & $6.2 \%$ of $16 \mathrm{pl}$ with $>90 \%$ stenosis \\
& & $2.0 \%$ of $49 \mathrm{pl}$ with ICA occlusion \\
\hline
\end{tabular}

were associated with more than $50 \%$ stenosis as demonstrated by ultrasonic carotid duplex scan. ${ }^{124}$

Furlan and Craciun studied the risk of stroke associated with CABG surgery in 144 patients with internal carotid artery (ICA) disease documented by angiography (11 with bilateral lesions). Ipsilateral stroke occurred in one among 90 patients with 50 to $90 \%$ ICA obstruction ( $1.1 \%$ ), in one among 16 patients with more than $90 \%$ ICA obstruction $(6.2 \%)$, and in one among 49 patients with total ICA occlusion $(2.0 \%)$. The authors concluded that asymptomatic unilateral ICA stenosis less than $90 \%$ or ICA occlusion did not increase the risk of stroke during coronary artery bypass surgery ${ }^{125}$ (Table III).

It is logical to maintain a higher perfusion pressure and flow than normal during $\mathrm{CPB}$, and to use EEG monitoring to evaluate cerebral perfusion in patients with carotid stenosis. Gibbs et al. have demonstrated that cerebral blood flow ipsilateral to ICA occlusion was inappropriately low. ${ }^{126}$ However, recent studies on cerebral blood flow monitoring in patients with severe carotid stenosis or occlusion during nonpulsatile hypothermic bypass showed no evidence for decreased cerebral perfusion. ${ }^{1 / 2,127}$

There is no evidence to justify routine prophylactic carotid endarterectomy for patients with asymptomatic carotid disease before cardiac surgery. ${ }^{128}$ Patients can undergo cardiac procedures without carotid surgery as safely as if the carotid artery were repaired. ${ }^{129}$

\section{SYMPTOMATIC CAROTID ARTERY DISEASE}

Patients with symptomatic carotid artery disease, on the other hand, have an increased risk of perioperative stroke if they are subjected to CBP. $14,130,131$ These patients need revascularization of both the carotid and coronary arteries, and the choice is between staged and combined operations. A staged approach with carotid endarterectomy as the first procedure may result in some patients dying of cardiac complications before coronary surgery can be undertaken. Conversely, initial coronary revascularization may result in a high incidence of fatal stroke. ${ }^{132}$ Under appropriate circumstances, both lesions can be treated simultaneously. ${ }^{132-135}$

The approach to the management of these patients varies among institutions. In general, each patient is assessed according to the severity of the disease, both clinically and anatomically, in each system. Staged procedures with carotid endarterectomy before coronary artery bypass is preferable for patients who have a low cardiac risk presenting with one- or two-vessel disease and stable angina. Combined procedures are appropriate for neurologically symptomatic patients who are at high cardiac risk presenting with left main coronary artery disease, severe multivessel lesions with inadequate collateral perfusion, or unstable angina. ${ }^{136,137}$

The combined carotid endarterectomy and coronary artery bypass procedure appears to be a logical approach for patients with high-risk cerebrovascular and coronary artery diseases, although it is not clear whether this approach increases or decreases the morbidity and mortality, compared with staged operations. A review of the combined procedures from 1972 to 1988 (a total of 1345 patients) revealed a mean operative mortality rate of $5.7 \%$, permanent stroke rate of $3.0 \%$, and myocardial infarction rate of $3.8 \% .^{138}$ These figures are unacceptable for elective CABG in most institutions, and many institutions have discontinued the combined procedure approach. On the other hand, the recent experience from the Massachusetts General Hospital is encouraging. From 1983 to 1987 , there was no significant difference in either operative mortality $(2.0 \%$ vs $2.2 \%)$ or perioperative stroke $(2.0 \%$ vs $0.6 \%)$ in patients undergoing combined procedures and isolated coronary bypass grafting, respectively, ${ }^{138}$

Few patients are suitable for the combined procedures: $9.5 \%$ of 679 carotid endarterectomies performed at the Johns Hopkins Hospital, ${ }^{139}$ and $2.8 \%$ of 9714 coronary artery bypass procedures at the Cleveland Clinic. ${ }^{140}$ Perler et al. found that mortality associated with the combined procedures was influenced by age, left main coronary artery disease, male sex, history of congestive heart failure, and presence of bilateral carotid disease. ${ }^{139}$ Until further prospective studies are performed, the authors expressed caution in recommending the combined approach in elderly candidates or in those with three or more of the above risk factors. 


\section{Perioperative cardiogenic embolic stroke}

Cardiogenic embolism accounts for 6 to $23 \%$ of all ischaemic strokes and is a frequent cause of fatal brain infarction. ${ }^{141}$ Although data are lacking, cardiogenic embolism probably accounts for many perioperative strokes. Cardiogenic embolism is difficult to diagnose with certainty. Yasaka et al. found that intracardiac thrombi were frequently detected by repeated echocardiographic examination in patients with cerebral embolism. Dehydration seems to accelerate thrombus formation that is reflected by a decrease in antithrombin III. ${ }^{142}$

As cardiogenic strokes tend to be functionally devastating, and occur without warning, the primary emphasis must centre on their prevention. Perioperative cardiogenic stroke is more likely to occur in patients with some cardiac diseases, and may be associated with diagnostic and therapeutic procedures done to the heart.

\section{Cardiac diseases}

Patients who are at high risk of cardiogenic embolism include those with atrial fibrillation, valvular heart disease and prosthetic heart valves. ${ }^{141}$, 143-145

\section{ATRIAL FIBRILLATION}

Reed $e t$ al. found that atrial fibrillation increased the risk of perioperative stroke following CABG threefold. ${ }^{120}$ Taylor et al. reported ten focal neurological deficits in a series of 453 patients undergoing CABG. Six of the deficits occurred in 86 patients who had postoperative atrial fibrillation (7\%), and four occurred in 367 patients who had no postoperative atrial fibrillation $(1 \%))^{146}$

Atrial fibrillation is found in $0.4 \%$ of the adult population; the prevalence increases with age, being $2-4 \%$ after 60 years of age. It is the mosi common underlying cardiac disorder predisposing to systemic embolism. In the Framingham Study, the risk of a cerebral infarct in patients with chronic atrial fibrillation was found to be 5.6 times greater than in patients with sinus rhythm. The risk of first stroke is $4.1 \%$ per year in patients with nonrheumatic atrial fibrillation, and $4.5 \%$ per year in patients with atrial fibrillation associated with rheumatic valve disease. Once cerebral embolism has occurred, the risk for recurrent stroke is considerably higher, with recurrence rates of approximately $20 \%$ for the first year and $37 \%$ for three years. ${ }^{147}$

Petersen and Hansen found that atrial fibrillation in the absence of rheumatic heart disease was associated with a more than five-fold increase in stroke incidence, whereas atrial fibrillation with rheumatic heart disease had a 17-fold increase when compared with patients without atrial fibrillation. ${ }^{148}$ The risk of embolism is particularly high at the onset of atrial fibrillation. 149,150

The first clinical presentation with an ischaemic stroke syndrome may not be the first episode of cardiogenic embolic brain infarction; cerebral emboli causing infarction may be asymptomatic. Silent cerebral infarctions are often demonstrated by computed tomogram in patients with chronic atrial fibrillation. ${ }^{151.152}$

Long-term warfarin therapy is indicated when atrial fibrillation is associated with documented systemic embolism or mitral valvular disease. 145, 153,154

\section{VALVULAR HEART DISEASES}

Rheumatic mitral valve disease is associated with a higher risk of systemic embolism than any other common form of heart disease. It is estimated that a patient with rheumatic mitral valve disease has at least a $20 \%$ chance of having a clinically detectable systemic embolus during the course of the disease. ${ }^{155}$ When patients with mitral valve disease develop atrial fibrillation, the risk of systemic embolization increases dramatically. Therefore, all patients with rheumatic mitral valve disease associated with chronic or paroxysmal atrial fibrillation, or who have documented systemic embolism, should receive long-term warfarin therapy sufficient to prolong the prothrombin time to 1.5 times control. ${ }^{143}$

Mitral valve prolapse is the most common valve disease in adults, and is present in 2.5 to $17 \%$ of the general population ${ }^{156-158}$ Although it is generally innocuous, mitral valve prolapse may be associated with an increased incidence of atrial fibrillation, mitral regurgitation, infective endocarditis and embolic phenomena. The exact role of mitral valve prolapse in cerebral ischaemia is not clear. ${ }^{159}$ Sandok and Giuliani reported a four-fold increase in strokes in persons with mitral valve prolapse compared to the normal population. ${ }^{160}$ However, in large prospective series of stroke patients, mitral valve prolapse is detected in only 0 to $5 \%$. $^{161-166}$

In young patients without other major risk factors for stroke, the presence of mitral valve prolapse may constitute a risk for cerebral ischaemia. ${ }^{167}$ However, the overall incidence of stroke in young individuals with mitral valve prolapse is low, approximately one per 6,000 per year, or $0.2 \% .{ }^{168}$ Patients with asymptomatic mitral valve prolapse need not be on antithrombotic therapy. However, if unexplained TIAs occur, long-term aspirin is recommended. ${ }^{143}$

Aortic valve disease is associated with a low frequency of systemic thromboembolism, and long-term antithrombotic therapy is not indicated. ${ }^{143}$

\section{PROSTHETIC HEART VALVES}

The risk of thromboembolism depends on the type and site of the valve. Tissue valves are generally less thrombogenic than mechanical valves. ${ }^{144,169}$ The velocity of blood flow across the mitral valve is less than across the 
aortic valve. With a greater deposition of platelets and fibrin on the mitral valve, the risk of emboli arising from the mitral prosthetic valve is therefore greater than that from the aortic prosthetic valve. ${ }^{170}$

Patients with mechanical prosthetic valves are at a significant risk for thromboembolism and require longterm anticoagulation, ${ }^{171}$ and also antiplatelet agents postoperatively. ${ }^{172}$ Patients with tissue valves also require anticoagulation during the first 6 to 12 postoperative weeks. Anticoagulation is required for all patients with prosthetic valves if they have chronic atrial fibrillation or a previously documented embolic event. ${ }^{171,173}$ The risk of embolism is reduced by therapy, but in about $2 \%$ of patients on long-term warfarin, the treatment is complicated by serious, frequent, intracranial haemorrhage. ${ }^{174,175}$

\section{PERIOPERATIVE MANAGEMENT OF PATIENTS ON}

\section{LONG-TERM ANTICOAGULANT THERAPY}

The cardiac lesions for which long-term warfarin therapy is recommended by the American College of Chest Physicians and the National Heart, Lung and Blood Institute to prevent systemic embolism and stroke include: (1) atrial fibrillation with a history of systemic emboli, mitral valve disease, cardiomyopathy or thyrotoxicosis, (2) mitral valve disease with a history of systemic emboli, chronic or paroxysmal atrial fibrillation, (3) mitral valve prolapse with atrial fibrillation, (4) mechanical prosthetic heart valves, and (5) bioprosthetic heart valves with mitral placement, history of systemic emboli, atrial fibrillation or left atrial thrombus. ${ }^{143-145}$

In patients receiving long-term anticoagulation therapy and undergoing noncardiac operations, maintenance of anticoagulation can be associated with perioperative bleeding, and discontinuation can lead to thromboembolism. ${ }^{176}$ For patients with isolated aortic prosthetic valves, warfarin should be discontinued two to three days before surgery to produce a normal prothrombin time on the day of operation, and resumed two days after the operation. ${ }^{176-178}$ Tinker and Tarhan found that discontinuing anticoagulation to restore the prothrombin time to within $20 \%$ of control did not cause excessive perioperative bleeding, and was not associated with thromboembolic complications. ${ }^{179}$ The risk of thromboembolism is greater in patients with mitral or combined prosthetic valves. In these patients, and in other patients at highest risk for thromboembolic complications, anticoagulation should be continued to within $24 \mathrm{hr}$ of their surgery. The warfarin effect may be reversed with parenteral vitamin $\mathrm{K}$ or fresh-frozen plasma. ${ }^{176.177}$ Intravenous heparin is started $12 \mathrm{hr}$ after the procedure when adequate haemostasis has been secured. The partial thromboplastin time is maintained at 1.5 to 2.5 times the levels of normal controls. When adequate surgical haemostasis is assured, usually three days after operation, oral anticoagulation with warfarin is resumed and the heparin is stopped when the prothrombin time reaches a therapeutic level. ${ }^{176,177}$

Alternatively, anticoagulation can be switched from warfarin to heparin. Heparin is started two to three days preoperatively, stopped 8 to $12 \mathrm{hr}$ before surgery, and restarted postoperatively as soon as haemostasis is assured. Warfarin is resumed two to three days later. Heparin is discontinued when the prothrombin time has returned to the desired range. ${ }^{178}$ For the patient with a high risk of thromboembolism, who has a prosthetic heart valve, chronic atrial fibrillation or persistent congestive heart failure, it may be safe to perform minor operations such as dental extractions or other procedures in accessible areas, while maintaining anticoagulation. ${ }^{178}$

\section{PERIOPERATIVE PROPHYLACTIC ANTIBIOTIC THERAPY}

Infective endocarditis may lead to septic embolism, causing ischaemic stroke and intracranial haemorthage. ${ }^{180,181}$ Prophylactic antibiotic coverage during the perioperative period is important to prevent endocarditis in patients with valvular disease and prosthetic valves. Davenport and Hart retrospectively reviewed the outcomes of 61 patients with 62 episodes of prosthetic valve endocarditis. Eleven patients (18\%) suffered an embolic stroke, usually within three days of diagnosis of endocarditis. No protective effect of anticoagulation therapy with warfarin was observed, and no specific risk of haemorrhagic stroke was evident with anticoagulant therapy. ${ }^{182}$ It appears that antibiotic treatment is more important than anticoagulation for preventing neurological complications in patients with prosthetic valve endocarditis.

\section{PATENT FORAMEN OVALE AND VENTRICULAR SEPTAL DEFECT}

Patent foramen ovale may be present in up to $40 \%$ of routine autopsies. ${ }^{183}$ Recent reports suggest paradoxical embolism is responsible for an increased incidence of stroke in patients with patent foramen ovale, ${ }^{184-186}$ and perioperative stroke due to paradoxical embolism has been reported. ${ }^{187,188}$ Black et al., using preoperative precordial echocardiography along with the Valsalva manoeuvre, detected right-to-left shunting in only six of a series of 101 patients scheduled for neurosurgical procedures in the sitting position. As a result of these findings, five of the six patients had their surgery performed either in the horizontal or in the prone position. Transoesophageal echocardiography further detected right-to-left shunting in four of these patients during surgery. ${ }^{189}$

Normally, the pressures in the left chambers of the heart are higher than in the right, but coughing or the Valsalva manoeuvre may increase right-sided pressures so that a venous thrombus may pass into the systemic circulation and lead to cerebral embolism.

Paradoxical embolism and stroke may occur through 
similar mechanisms in patients with other intracardiac shunts, such as ventricular septal defect. ${ }^{190}$ Ventricular septal defect is found in 0.25 to $1 \%$ in autopsy studies, but its true incidence is difficult to assess, as many of the defects close spontaneously. ${ }^{191}$

The therapeutic implications in the perioperative period for patients with intracardiac shunts are obvious. Sources of venous emboli, such as deep venous thrombosis and those introduced through venous access lines, are to be prevented, and pressure increases on the right side of the heart, such as coughing and Valsalva manoeuvre, should be avoided.

\section{Diagnostic and therapeutic procedures}

\section{CARDIOVERSION}

Systemic embolism may complicate cardioversion of atrial fibrillation, especially in patients with mitral stenosis, prosthetic mitral valves, history of embolic phenomena, enlarged hearts, or congestive heart failure. Bjerkelund and Orning reported embolization complicating cardioversion in $5.3 \%$ of patients without anticoagulation, but in only $0.8 \%$ in those receiving anticoagulant therapy. ${ }^{192}$ It is recommended that anticoagulation be started three weeks before elective cardioversion to maintain the prothrombin time in the therapeutic range of 1.2-1.5 times control. Anticoagulation should be continued for at least four weeks after cardioversion. This will reduce the formation of a new clot in a noncontractile atrium if mechanical resumption of atrial activity is delayed. ${ }^{145}$

\section{PACEMAKER INSERTION}

Disturbances of cardiac rhythm and manipulation of wires in the heart may generate thrombi. However, the risk of stroke associated with the insertion of intravenous endocardial pacemakers is not known. Patients with the sick sinus syndrome are at risk for cardioembolic stroke. Stroke after pacemaker insertion for sick sinus syndrome occurs often in the presence of paroxysmal or sustained atrial fibrillation. Pacing with a ventricular-demand pacemaker does not appear to be protective. ${ }^{193}$

\section{CORONARY ARTERIOGRAPHY AND CORONARY ANGIOPLASTY}

Stroke occasionally complicates coronary arteriography. Adams et al., in a survey of complications in 46,904 cases of coronary arteriography in 1970 and 1971 , found that the incidence of cerebral embolism was $0.23 \%$. The risk was higher when the femoral route was used for catheter access. ${ }^{194}$ Bourassa and Noble reported central nervous complications in ten of 5250 cases. Five patients had transient cerebral ischaemia, two had temporary disorientation, and three had transient blurred vision. ${ }^{195}$ Transient
TABLE IV CNS complications associated with coronary arteriography

\begin{tabular}{|c|c|c|}
\hline Authors & Cases & CNS complications \\
\hline Adams el al. ${ }^{194}$ & 46,904 & $0.23 \%$ cerebral embolisn \\
\hline Bourassa el al. ${ }^{195}$ & 5,250 & $\begin{array}{l}10 \text { TIA, disorientation, recurrent } \\
\text { blurred vision }\end{array}$ \\
\hline Dawson ef al. 197 & $>1,000$ & 10 CNS dysfunction, mostly embolic \\
\hline Sones ${ }^{198}$ & 52,953 & 4 cerebral emboli with long term deficits \\
\hline Lockwood el al. ${ }^{199}$ & 30,000 & 37 CNS complications \\
\hline
\end{tabular}

visual disturbance occasionally complicates cardiac catheterization. Oliva and Scherokman reported computedtomography-documented occipital lobe infarction in two patients with this complication. ${ }^{196}$ Dawson and Fischer, in a survey of over 1000 cases, found ten cases of central nervous dysfunction. Nine of these were embolic in origin, mostly with focal disorder in the vertebrobasilar territory. ${ }^{197}$ Sones found four cases of cerebral emboli resulting in long-term deficits among 52,953 cases. ${ }^{198}$ In a study of 30,000 cardiac catheterizations, Lockwood et al. found 37 central nervous system complications, with two global ischaemia, 15 in the carolid, and 20 in the vertebrobasilar distribution. While the neurological deficit resolved in 19, and persisted in 16, two of the patients died. Embolization and hypotension were responsible in most of the cases. Cerebrovascular disease, ventricular hypokinesia, mural thrombus and valvular disease were found to be contributing factors. ${ }^{199}$

From these studies, the overall incidence of stroke associated with coronary arteriography is less than $1 \%$ (Table IV).

Stroke has been reported following percutaneous transluminal coronary angioplasty. Although stroke was not listed in an initial report of 631 cases from the registry of the National Heart, Lung, and Blood Institute, ${ }^{200}$ five central nervous system events were seen in a subsequent report of 1500 patients $(0.3 \%)$. There was one anoxic encephalopathy, one cerebrovascular accident, and three transient neurological deficits. ${ }^{201} \mathrm{Galbreath}$ et al. reported a similar experience, with four $(0.2 \%)$ central nervous system complications among 1829 patients having 1968 percutaneous transluminal coronary angioplasties. One patient had a TIA, two had hemispheric infarcts, and one had a brainstem infarct. ${ }^{202}$

\section{Conclusion}

Stroke, defined as a focal neurological deficit, in the perioperative period is an uncommon but devastating complication. Although medical risk factors for stroke are well defined in the general population, no large scale data are available that identify the importance of the individual risk factors as a cause of perioperative stroke. In most clinical situations including general surgery, carotid 
endarterectomy, and cardiac surgery involving CPB, thromboembolism appears to be the most important cause of perioperative stroke.

Cardiogenic embolism is a recognized complication of atrial fibrillation and valvular heart disease, and most perioperative strokes probably have a similar origin. With adequate monitoring and protection of the cerebral circulation, stroke associated with carotid surgery is most likely due to thromboembolism. Air and particle emboli are also the major causes of neurological deficits associated with CPB and open ventricle surgery. Patients with asymptomatic carotid disease do not appear to be at a higher risk of perioperative stroke than those with normal arteries. However, symptomatic carotid disease or critical carotid stenosis may increase this risk.

Because of prolonged changes of regional cerebral blood flow and enhanced thrombin activity following a stroke, elective surgery should be postponed for six to ten weeks. Anaesthetic agents such as isoflurane and thiopentone have cerebral protection properties, but they have to be given in sufficient doses to produce burst suppression in the EEG. Their use has been recommended in high-risk patients or procedures, but can be associated with cardiovascular instability and prolonged emergence from anaesthesia.

\section{Acknowledgement}

I would like to express my appreciation to our programmer analyst, Janet Lee Haines, for her advice and assistance in preparing this manuscript.

\section{References}

I Sotaniemi KA. Cerebral outcome after extracorporeal circulation. Comparison between prospective and retrospective evaluations. Arch Neurol 1983; 40: 75-7.

2 Silverstein A, Krieger HP. Neurologic complications of cardiac surgery. Arch Neurol 1960; 5: 601-5.

3 Gilman $S$. Cerebral disorders after open-heart operations. N Engl J Med 1965; 272: 489-94.

4 Brierley $J B$. Brain damage complicating open-heart surgery: a neuropathological study of 46 patients. Proc $R$ Soc Med 1967; 60: 858-9.

5 Javid $H, T$, fo HM, Najafi $H$ et al. Neurological abnormalities following open-heart surgery. J Thorac Cardiovasc Surg 1969; 58: 502-9.

6 Lytle BW, Cosgrove DM, Taylor PC et al. Primary isolated aortic valve replacement. J Thorac Cardiovasc Surg 1989; 97: 675-94.

7 Sotaniemi KA. Brain damage and neurological outcome after open-heart surgery. J Neurol Neurosurg Psychiatry 1980; 43: 127-35.
8 Lee MC, Geiger J, Nicoloff D et al. Cerebrovascular complications associated with coronary artery bypass (CAB) procedures. Stroke 1979; 10: 107.

9 Gonzalez-Scarano F, Hurlig H. Neurologic coniplications of coronary artery bypass grafting: case-control study. Neurology 1981; 31: 1032-5.

10 Martin WRW, Hashimoto SA. Siroke in coronary bypass surgery. Can J Neurol Sci 1982; 9: 21-6.

11 Bojar RM, Najafi H, Delaria GA et al. Neurological complications of coronary revascularization. Ann Thorac Surg 1983; 36: 427-32.

12 Coffey CE, Massey W, Roberts KB et al. Natural history of cerebral complications of coronary arlery bypass graft surgery. Neurology 1983; 33: 1416-21.

13 Shaw PJ, Bates D, Cartlidge NEF et al. Early neurological complications of coronary artery bypass surgery. BMJ 1985; 291: 1384-7.

14 Breuer AC, Furlan AJ, Hanson MR et al. Central nervous system complicalions of coronary artery bypass graft surgery: prospective analysis of 421 patients. Stroke 1983; 14: 682-7.

15 Schober $R$, Herman MM. Neuropathology of cardiac transplantation: survey of 31 cases. Lancet 1973; 962-7.

16 Montero CG, Nartinez AJ. Neuropathology of heart transplantation: 23 cases. Neurology 1986; 36: 1149-54.

17 Fink ME, Drusin R, Lamb J et al. Cerebrovascular complications of cardiac transplantation. Stroke 1987; 18: 294

18 Sila $C A$. Spectrum of neurologic events following cardiac transplantation. Stroke 1989; 24: 19-23.

19 Slogoff A, Girgis KZ, Keats AS. Etiologic factors in neuropsychiatric complications associated with cardiopulmonary bypass. Anesth Analg 1982; 61: 903-11.

20 Gallagher EC, Pearson DT. Ultrasonic identification of sources of gaseous microemboli during open heart surgery. Thorax 1973; 28: 295-305.

21 Oka Y, Moriwaki KM, Hong Y et al. Detection of air emboli in the left heart by $\mathrm{M}$-mode transesophageal echocardiography following cardiopulmonary bypass. Anesthesiology 1985; 63: 109-13.

22 Lawrence GH, McKay HA, Sherensky RT. Effective measures in the prevention of intraoperative aeroembolus. J Thorac Cardiovasc Surg 1971; 62: 731-5.

23 Padula RT, Eisenstat TE. Bronstein MH, Camishion $R C$. Intracardiac air following cardiotomy. Location, causative factors, and a method for removal. J Thorac Cardiovasc Surg 1971; 62: 736-42.

24 Oka Y, Inoue T, Hong Y et al. Retained intracardiac air. Transesophageal echocardiography for definition of incidence and moniloring removal by improved techniques. J Thorac Cardiovasc Surg 1986; 91: 329-38. 
25 Robicsek F, Duncan GD. Retrograde air embolization in coronary operations. J Thorac Cardiovasc Surg 1987; 94: 110-4.

26 Bagdonas AA, Stuckey JH, Dennis C et al. The role of position in the development of cerebral air embolism following air injection at the base of the aorta. Surg Forum 1960; 10: 653-6.

27 Mills NL, Ochsner JL. Massive air embolism during cardiopulmonary bypass. J Thorac Cardiovasc Surg 1980; 80: 708-17.

28 Wells DG, Podolakin W, Mohr M et al. Nitrous oxide and cerebrospinal fluid markers of ischaemia following cardiopulmonary bypass. Anaesth Intensive Care 1987; 15: $431-5$.

29 Gardner TJ, Horneffer PJ, Manolio TA el al. Stroke following coronary artery bypass grafting: a ten-year sludy. Ann Thorac Surg 1985; 40: 574-81.

30 McKibbin DW, Bulkley BH, Green WR et al. Fatal cerebral atheromatous embolization after cardiopulmonary bypass. J Thorac Cardiovasc Surg 1976; 71: 741-5.

31 Harman RB, Harrison EE, Pupello DF et al. Characteristics of left ventricular thrombus resulting in perioperative embolism. A complication of coronary artery bypass grafting. J Thorac Cardiovasc Surg 1983; 86: 706-9.

32 Coselli JS, Crawford ES. Aortic valve replacement in the patient with extensive calcification of the ascending aorta (the porcelain aorta). J Thorac Cardiovasc Surg 1986; 91: 184-7.

33 Evans EA, Wellington JS. Emboli associated with cardiopulmonary bypass. J Thorac Cardiovasc Surg 1964: 48: 323-30.

34 Reed CC, Romagnoli A, Taylor DE, Clark DK. Particulate matter in bubble oxygenators. J Thorac Cardiovasc Surg 1974; 68: 971-4.

35 Guidoin RG, Awad JA, Laperche Y et al. Nature of deposits in atubular membrane oxygenator after prolonged extracorporeal circulation. A scanning electron microscope study. J Thorac Cardiovasc Surg 1975; 69: 479-91

36 Kessler J. Patterson RH. The production of microemboli by various blood oxygenators. Ann Thorac Surg 1970; 9: 221-8.

37 Padayachee TS, Parsons S, Theobold $R$ et al. The effect of arterial filtration on reduction of gaseous microemboli in the middle cerebral artery during cardiopulmonary bypass. Ann Thorac Surg 1988; 45: 647-9.

38 Blauth Cl. Smith PL. Arnold JV et al. Influence of oxygenator type on the prevalence and extent of microembolic retinal ischemia during cardiopulmonary bypass. Assessment by digital image analysis. J Thorac Cardiovasc Surg 1990; 99: 61-9.

39 Young JA, Kisker CT, Doty DB. Adequate anticoagulation during cardiopulmonary bypass determined by activated clotting time and the appearance of fibrin monomer. Ann Thorac Surg 1978; 26: 231-40.

40 Dutron RC, Edmunds LH, Hutchinson JC, Roe BB. Platclet aggregate emboli produced in patients during cardiopulmonary bypass with membrane and bubble oxygenators and blood filters. J Thorac Cardiovasc Surg 1974; 67: $258-65$.

41 Loop FD, Szabo J, Rowlinson RD, Urbanek K. Events related to microembolism during extracorporeal perfusion in man: effectiveness of in-line filtration recorded by ultrasound. Ann Thorac Surg 1976; 21: 412-20.

42 Semb BKH, Pedersen T, Hatteland $K$ ef al. Doppler ultrasound estimation of bubble removal by various arterial line filters during extracorporeal circulation. Scand J Thorac Cardiovasc Surg 1982; 16: 55-62.

43 Solis RT, Noon GP, Beall AC, DeBakey ME. Particulate microembolism during cardiac operation. Ann Thorac Surg 1974; 17: 332-44.

44 Solis RT, Kennedy PS, Beall AC Jr et al. Cardiopulmonary bypass. Microembolization and platelet aggregation. Circulation 1975; 52: 103-8.

45 Aberg $T$, Kihlgren $M$. Cerebral protection during openheart surgery. Thorax $1977 ; 32: 525-33$.

46 Carlson RG, Lande AJ, Landis B et al. The LandeEdwards membrane oxygenator during heart surgery. Oxygenation, microemboli counts, and Bender-Gestalt visual molor test scores. J Thorac Cardiovasc Surg 1973; 66: 894-905.

47 Garvey JW, Wilner A, Wolpowitz $A$ et al. The effect of arterial filtralion during open heart surgery. Circulation 1983; 68 (Suppl II): 125-8

48 Newberg LA, Michenfelder JD. Cerebral protection by isoflurane during hypoxemia or ischemia. Anesthesiology 1983; 59: 29-35.

49 Todd MM, Drummond JC. A comparison of the cerebrovascular and metabolic effects of halothane and isoflurane in the cat. Anesthesiology 1984: 60: 276-82.

50 Baughman VL, Hoff man WE, Miletich DJ et al. Neurologic outcome in rats following incomplete cerebral ischemia during halothane, isoflurane, or $\mathrm{N}_{2} \mathrm{O}$. Anesthesiology 1988; 69: 192-8.

51 Newberg LA. Milde JH, Michenfelder JD. The cerebral metabolic effects of isoflurane at and above concentrations that suppress cortical electrical activity. Anesthesiology 1983; 59: 23-8.

52 Nehis DG, Todd MM, Spetzler RF et al. A comparison of the cerebral protective effects of isoflurane and barbiturates during temporary focal ischemia in primates. Anesthesiology 1987; 66: 453-64.

53 Young WL, Prohovnik I, Correll JW et al. Cerebral blood flow and metabolism in patients undergoing anesthesia 
for carotid endarterectomy. A comparison of isoflurane, halothane, and fentanyl. Anesth Analg 1989; 68:

712-7.

54 Newberg LA, Milde JH, Michenfelder JD. Systemic and cerebral effects of isoflurane-induced hypotension in dogs. Anesthesiology 1984; 60: 541-6.

55 Newman B, Gelb AW, Lam AM. The effect of isofluraneinduced hypotension on cerebral blood flow and cerebral metabolic rate for oxygen in humans. Anesthesiology 1986; 64: 307-10.

56 Artru AA. Cerebral metabolism and EEG during combination of hypocapnia and isoflurane-induced hypotension in dogs. Anesthesiology 1986; 65: 602-8.

57 Mutch WAC, Malo LA, Ringaert KHA. Phenylephrine increases regional cerebral blood flow following hemorrhage during isoflurane-oxygen anesthesia. Anesthesiology 1989; 70: 276-9.

58 Rusa TS, Murch WAC. Regional cerebral blood flow following hemorrhage during isoflurane anesthesia in the rabbit: comparison of techniques to support blood pressure. Anesthesiology 1989; 70: 978-83.

59 Messick JM Jr, Casement B, Sharbrough FW et al. Correlation of regional cerebral blood flow ( $\mathrm{CBBF}$ ) with EEG changes during isoflurane anesthesia for carotid endarterectomy: critical rCBF. Anesthesiology 1987; 66: 344-9.

60 Michenfelder JD, Sundt TM, Fode N, Sharbrough FW. Isoflurane when compared to enflurane and halothane decreases the frequency of cerebral ischemia during carotid endarterectomy. Anesthesiology 1987; 67: 336-40.

61 Woodcock TE, Murkin JM, Farrar JK et al. Pharmacologic EEG suppression during cardiopulmonary bypass: cerebral hemodynamic and metabolic effects of thiopental or isoflurane during hypothermia and normothermia. Anesthesiology 1987; 67: 218-24.

62 Slogoff S, Keats AS. Randomized trial of primary anesthetic agents on outcome of coronary artery bypass operations. Anesthesiology 1989; 70: 179-99.

63 Tuman KJ, McCarthy RJ, Spiess BD el al. Does choice of anesthetic agent significantly affect outcome after coronary artery surgery? Anesthesiology 1989; 70: 189-98.

64 Inoue K, Reichelt W, El-Banayosy A et al. Does isoflurane lead to a higher incidence of myocardial infarction and perioperative dea th than enflurane in coronary artery surgery? A clinical study of 1178 patients. Anesth Analg 1990; 71: 469-74.

65 Steen PA, Newberg L, Milde JH, Michenfelder JD. Hypothermia and barbiturates: individual and combined effects on canine cerebral oxygen consumption. Anesthesiology 1983; 58: 527-32.

66 Michenfelder JD. The interdependency of cerebral functional and metabolic effects following massive doses of thiopental in the dog. Anesthesiology 1974; 41: 231-6.
67 Astrup J, Sorensen PM, Sorensen HR. Inhibition of cerebral oxygen and glucose consumption in the dog by hypothermia, pentobarbital, and lidocaine. Anesthesiology 1981; 55: 263-8.

68 Branston JH. Hope T, Symon L. Barbiturates in focal ischemia of primate contex: effects on blood flow distribution, evoked potential and extracellular potassium. Stroke 1979; 10: 647-53.

69 Selman WR. Spetzler RF, Roessmam UR et al. Barbiturate-induced coma therapy for focal cerebral ischemia. Effect after temporary and permanent MCA occlusion. J Neurosurg 198I; 55: 220-6.

70 Nussmeier NA, Arlund C, Slogoff S. Neuropsychiatric complications after cardiopulmonary bypass: cerebral protection by a barbiturate. Anesthesiology 1986; 64: 165-70.

71 McMurrey JD, Bermard WF, Taren JA, Bering EA. Studies on hypothermia in monkeys: the effect of hypothermia on the prolongation of permissible time of total occlusion of the afferent circulation of the brain. Surg Gynecol Obstet 1956; 102: 75-86.

72 Lafferty JJ, Keykhah MM, Shapiro HM et al. Cerebral hypometabolism obtained with deep pentobarbital anesthesia and hypothermia $\left(30^{\circ} \mathrm{C}\right)$. Anesthesiology $1978 ; 49$ : 159-64.

73 Gordon RJ, Ravin M, Daicoff GR, Rawitscher RE. Effects of hemodilution on hypotension during cardiopulmonary bypass. Anesth Analg 1975; 54: 482-8.

74 Williams JJ, Marshall BE. A fresh look at an old question. Anesthesiology 1982: 56: 1-2.

75 Reeves $R B, R a h n H$. Patterns in vertebrate acid-base regulation. In: Wood SC, Lenfant C. (Eds.). Evolution of Respiratory Processes: A Comparative Approach. New York: Marcel Dekker, Inc. 1979; 225-52.

76 McConnel DH, White FN, Nelson RL et al. Importance of alkalosis in maintenance of "ideal" blood pH during hyopothermia. Surg Forum 1975; 26: 263-5.

77 Ohmura A, Wong $K C$, Westenskow DR. Shaw CL. Effects of hypocarbia and normocarbia on cardiovascular dynamics and regional circulation in the hypothermic dog. Anesthesiology 1979; 50: 293-8.

78 Henriksen L, Hjelms $E$, Lindeburgh $T$. Brain hyperperfusion during cardiac operations. J Thorac Cardiovasc Surg 1983; 86: 202-8.

79 Govier AV, Reves JG, MCKay RD et al. Factors and their influence on regional cerebral blood flow during nonpulsatile cardiopulmonary bypass. Ann Thorac Surg 1984; 38: 592-600.

80 Prough DS, Stump DA, Roy RC et al. Response of cerebral blood flow to changes in carbon dioxide tension during hypothermic cardiopulmonary bypass. Anesthesiology 1986; 64: 576-81.

81 Hägerdal $M$, Harp JR, Siesjö $B K$. Influence of changes in 
arterial $\mathrm{PCO}_{2}$ on cerebral blood flow and cerebral energy state during hypothermia in the rat. Acta Anaesth Scand 1975; 57 (Suppl): 25-33.

82 Murkin JM. Farrar JK, Tweed WA et al. Cerebral autoregulation and flow/metabolism coupling during cardiopulmonary bypass: the influence of $\mathrm{PaCO}_{2}$. Anesth Analg 1987; 66: 825-32.

83 Habal SM, Weiss MB, Spomitz HM et al. Effects of pulsatile and nonpulsatile coronary perfusion on performance of the canine left ventricle. J Thorac Cardiovasc Surg 1976; 72: 742-5.

84 German JC, Chalmers GS, Hirai J et al. Comparison of nonpulsatile and pulsatile extracorporeal circulation in renal tissue perfusion. Chest 1972; 61: 65-9.

85 Taylor KM, Bain WH, Maxted KJ et al. Comparative studies of pulsatile and nonpulsatile flow during CPB. I. Pulsatile system employed and its hematologic effects. J Thorac Cardiovase Surg 1978; 75: 569-73.

86 Taylor KM. Wright GS, Reid JM et al. Comparative studies of pulsatile and nonpulsatile flow during CPB. II. The effects on adrenal secretion of cortisol. J Thorac Cardiovasc Surg 1978; 75: 574-8.

87 Taylor KM, Wright GS, Bain WH et al. Comparative studies of pulsatile and nonpulsatile flow during CPB III. Response of anterior pituitary gland to thyrotropinreleasing. J Thorac Cadiovasc Surg 1978; 75: 579-84.

88 Kritikou PE, Branthwaite MA. Significance of changes in cerebral electrical activity at onset of cardiopulmonary bypass. Thorax 1977; 32: 534-8.

89 Mavroudis $C$. To pulse or not to pulse. Ann Thorac Surg 1978; 25: 259-71.

90 Edmunds $L H$. Pulseless cardiopulmonary bypass. J Thorac Cardiovasc Surg 1982; 84: 800-4.

91 Philbin DM, Hickey PR, Buckley $M$. Should we pulse? J Thorac Cardiovasc Surg 1982; 84: 805-6.

92 Juneja I, Flynn RE, Berger RL. The arterial and venous pressures and the electroencephalogram during open heart surgery. Acta Neurol Scand 1972; 48: 163-8.

93 Stockard JJ, Bickford RG, Schauble JF. Pressuredependent cerebral ischemia during cardiopulmonary bypass. Neurology 1973; 23: 521-9.

94 Stockard JJ, Bickford RG, Myers RR et al. Hypotensioninduced changes in cerebral function during cardiac surgery. Stroke 1974; 5: 730-46.

95 Branthwaire MA. Detection of neurological damage during open-heart surgery. Thorax 1973; 28: 464-72.

96 Ellis RJ, Wisniewski A, Potts $R$ et al. Reduction of flow rate and arterial pressure at moderate hypothermia does not result in cerebral dysfunction. J Thorac Cardiovasc Surg 1980; 79: 173-80.

97 Ames A III, Wright RL, Kowada M et al. Cerebral ischemia: Il. The no-reflow phenomenon. Am J Pathol 1968; 52: 437-53.
98 Cantu RC, Ames A III, Digiacimto G, Dixon J. Hypotension: a major factor limiting recovery from cerebral ischemia. J Surg Res 1969; 9: 525-9.

99 Hekmatpanah J. Cerebral circulation and perfusion in experimental increased intracranial pressure. J Neurosurg 1970; 32: 21-9.

100 Hekmatpanah J. Cerebral blood flow dynamics in hypotension and cardiac arrest. Neurology 1973; 23: 174-80.

101 Wiroszka $M M$, Tamura $H$, Indeglia $R$ et al. Electroencephalographic changes and cerebral complications in open-heart surgery. J Thorac Cardiovasc Surg 1973; 66: 855-64.

102 Salerno TA, Lince DP, White DN et al. Monitoring of electroencephalogram during open-heart surgery. A prospective analysis of 118 cases. J Thorac Cardiovasc Surg 1978; 76: 97-100.

103 Schwartz MS, Colvin MP, Prior PF et al. The cerebral function monitor. Its value in predicting the neurological outcome in patients undergoing cardiopulmonary bypass. Anaesthesia 1973: 28: 611-8.

104 Nevin M. Colchester ACF, Adams S, Pepper JR. Predic tion of neurological damage after cardiopulmonary bypass surgery. Use of the cerebral function analysing monitor. Anaesthesia 1989; 44: 725-9.

105 El-Fiki $M$, Fish $K J$. Is the EEG a useful monitor during cardiac surgery? A case report. Anesthesiology 1987; 67: 575-8.

106 Jones BR, Scheller MS. Perfusion pressure and electroencephalographic changes during cardiopulmonary bypass. J Clin Monit 1989; 5: 288.

107 Levy WJ. Quantitative analysis of EEG changes during hypothermia. Anesthesiology 1984; 60: 291-7.

108 Sebel PS, Bovill JG, Wauquier A, Rog P. Effects of high-dose fentanyl anesthesia on the electroencephalogram. Anesthesiology 1981; 55: 203-II.

109 Bovill JG, Sebel PS, Wauquier A, Rog P. Electroencephalographic effects of sufentanil anaesthesia in man. $\mathrm{Br}$ J Anaesth 1982; 54: 45-52.

110 Levy WJ, Shapiro HM, Mearhe E. The identification of rhythmic EEG artifacts by power-spectrum analysis. Anesthesiology 1980; 53: 505-7.

111 Steele ER, Albin MS, Monts JL, Harman PK. Compressed spectral array EEG monitoring during coronary bypass surgery in a patient with vertebrobasilar artery insufficiency. Anesth Analg 1987; 66: 27I-3.

112 Von Reutern G-M, Hetzel A, Birnbaum D, Schlosser $V$. Transcranial Doppler ultrasonography during cardiopulmonary bypass in patients with severe carotid stenosis or occlusion. Stroke 1988; 19: 674-80.

113 Pasquale GD, Andreoli A, Pinelli $G$ et al. Cerebral ischemia and asymptomatic coronary artery disease: a prospective study of 83 patients. Stroke 1986; 17 : 1098-101. 
114 Jones EL, Craver JM. Michalik RA et al. Combined carotid and coronary operations: when are they necessary? J Thorac Cardiovasc Surg 1984: 87: 7-16.

115 Herizer $N R$, Lees $C D$. Fatal myocardial infarction following carotid endarterectomy: three hundred thirtyfive patients followed 6-11 years after operation. Ann Surg 1981; 194: 212-8.

116 Thompson JE, Austin DJ, Patman RD. Carotid endarterectomy for cerebrovascular insufficiency: longterm results in 592 patients followed up to thirteen years. Ann Surg 1970; 172: 663-79.

117 DeWeese JA, Rob CG, Satran R et al. Results of carotid endarterectomies for transient ischemic attacks - five years later. Ann Surg 1973; 178: 258-64.

118 Mackey WC, O'Donnell TF Jr, Callow AD. Cardiac risk in patients undergoing carotid endarterectomy: impact on perioperative and long-term mortality. J Vasc Surg 1990; 11: 226-34.

119 Shaw PJ, Bates D. Carllidge NEF et al. Neurologic and neuropsychological morbidity following major surgery: comparison of coronary artery bypass and peripheral vascular surgery. Stroke 1987; 18: 700-7.

120 Reed GL III, Singer DE, Picard EH, DeSanctis RW. Stroke following coronary-artery bypass surgery. A case-control estimate of the risk from carotid bruits. N Engl J Med 1988; 319: 1246-50.

121 Kartchner MM, McRne LP. Non-invasive evaluation and management of the 'asymptomatic' carotid bruit. Surgery $1977 ; 82: 840-7$.

122 Barnes RW, Liebman PR, Marszalek PB et al. The natural history of asymptomatic carotid disease in patients undergoing cardiovascular surgery. Surgery 1981; 90: 1075-83.

123 Gutierrez IZ, Barone DL, Makula PA, Currier C. The risk of perioperative stroke in patients with asymptomatic carotid bruits undergoing peripheral vascular surgery. Am Surg 1987; 53: 487-9

124 Ivey TD, Strandness $D E$, Williams $D B$ et al. Management of patients with carolid bruit undergoing cardiopulmonary bypass. J Thorac Cardiovasc Surg 1984; 87 : 183-9.

125 Furlan $A J$, Craciun AR. Risk of stroke during coronary artery bypass graft surgery in patients with internal carotid artery disease documented by angiography. Stroke 1985; 16: 797-9.

126 Gibbs $J M$, Wise RJS, Leenders $K L$, Jones $T$. Evaluation of cerebral perfusion reserve in patients with carotid artery occlusion. Lancet 1984; 1: 182-6.

127 Basino FG, Reves JG, Prough DS, Stump DA. Cerebral blood flow during cardiopulmonary bypass in a patient with occlusive cerebrovascular disease. Journal of Cardiothoracic Anesthesia 1989; 3: 87-90.

128 Barnes $R W$. Asymptomatic carotid disease in patients undergoing major cardiovascular operations: can prophylactic endarterectomy be justified? Ann Thorac Surg 1986; 42 (Suppl): 36-40.

129 Brener BJ, Brief DK, Alpert J et al. The risk of stroke in patients with asymptomatic carolid stenosis undergoing cardiac surgery: a follow-up study. J Vasc Surg 1987; 5: 269-79.

130 Mehigan JT, Bush WS, Pipkin RD, Fogarry TJ. A planned approach to coexistent cerebrovascular disease in coronary artery bypass candidates. Arch Surg 1977; 112: 1403-9.

131 Gravlee GP, Cordell AR, Graham JE et al. Coronary revascularization in patients with bilateral internal carotid occlusions. J Thorac Cardiovasc Surg 1985; 90 : 921-5.

132 Ennix CL Jr, Lawrie GM, Morris GC Jr et al. Improved results of carotid endarterectomy in patients with symptomatic coronary disease: an analysis of 1546 consecutive carotid operations. Stroke 1979; 10: 122-5.

133 Morris GC Jr, Ennix CL Jr, Lawrie GM et al. Management of co-existent carotid and coronary artery occlusive atherosclerosis. Cleveland Clin Quarterly 1978; 45: 125-7.

134 Rice PL, Pifarre R, Sullivan HJ et al. Experience with simultaneous myocardial revascularization and carotid endarterectomy. J Thorac Cardiovasc Surg 1980; 79: 922-5.

135 Craver JM, Murphy DA, Jones EL et al. Concomitant carotid and coronary artery reconstruction. Ann Surg 1982; 195: 7/2-20

136 Urschel HC Jr. Management of concomitent coronary and carotid artery obstructive disease. Cleve Clin J Med 1978; 45: 128-9.

137 Graor RA. Hetzer NR. Management of coexistent carotid artery and coronary artery disease. Stroke 1988; 19: $1441-4$.

138 Cambria RP, Ivarsson BL, Akins CW et al. Simultaneous carotid and coronary disease: safety of the combined approach. J Vase Surg 1989; 9: 56-64.

139 Perler BA, Burdiek JF, Minken SL, Williams GM. Should we perform carotid endarterectomy synchronously with cardiac surgical procedures? J Vase Surg 1988; 8: 402-9.

140 Hertzer NR, Loop FD, Beven EG et al. Surgical staging for simultaneous coronary and carotid disease: a study including prospective randomization. J Vasc Surg 1989; 9: 455-63.

141 Sherman DG, Dyken ML, Fisher $M$ et al. Cerebral embolism. Chest 1986; 89 (Suppl): 82-98.

142 Yasaka M, Yamaguchi T, Miyashita T el al. Predisposing factors of recurrent embolization in cardiogenic cerebral embolism. Stroke 1990; 21: 1000-7. 
143 Levine HJ, Pauker SG, Saizman EW. Antithrombotic therapy in valvular heart disease. Chest 1986;89 (Suppl): $36-45$.

144 Stein PD, Collins JC Jr, Kantrowitz A. Antithrombotic therapy in mechanical and biological prosthetic heart valves and saphenous vein bypass grafts. Chest 1986; 89 (Suppl): 46-53.

145 Dunn M, Alexander J, de Silva R, Hildner F. Antithrombotic therapy in atrial fibrillation. Chest 1986; 89 (Suppl): 68-74.

146 Taylor GJ, Malik SA, Colliver JA et al. Usefulness of atrial fibrillation as a predictor of stroke after isolated coronary artery bypass grafting. Am J Cardiol 1987; 60: 905-7.

147 Wolf PA, Dawber TR, Thomas HE, Kannel WB. Epidemiological assessment of chronic atrial fibrillation and risk of stroke: the Framingham Study. Neurology 1978; 28: 973-7.

148 Petersen P, Hansen JM. Stroke in thyrotoxicosis with atrial fibrillation. Stroke 1988; 19: 15-8.

149 Petersen P, Godtfredsen J. Embolic complications in paroxysmal atrial fibrillation. Stroke 1986; 17: 622-6.

150 Petersen $P$. Thromboembolic complications in atrial fibrillation. Stroke 1990; 21:4-13.

151 Petersen P, Madsen EB, Brun B et al. Silent cerebral infarction in chronic atrial fibrillation. Stroke 1987; 18: $1098-100$.

152 Kempster PA, Gerraty RP, Gates PC. Asymptomatic cerebral infarction in patients with chronic atrial fibrillation. Stroke 1988; 19: 955-7.

153 Halperin JL. Harl RG. Atrial fibrillation and stroke. New ideas, persisting dilemmas. Stroke 1988; 19: 937-41.

154 Flegel KM, Hanley J. Risk factors for stroke and other embolic events in patients with nonrheumatic atrial fibrillation. Stroke 1989; 20: 1000-4.

155 Levine $H J$. Which atrial fibrillation patients should be on chronic anticoagulation? J Cardiovasc Med 1981; 6 : 483-7.

156 Savage DD, Garrison RJ, Devereux RB et al. Mitral valve prolapse in the general population. I. Epidemological features: the Framingham Study. Am Heart J 1983; 106: 571-5.

157 Feltes $T F$, Wilcox WD. Mitral valve prolapse in adolescents. In: Julian DG, Wenger NK (Ed.). Cardiac Problems of the Adolescent and Young Adult. London: Butterworths, 1985.

158 Levy D. Savage D. Prevalence and clinical features of mitral valve prolapse. Am Heart J 1987; 113: 1281-90.

159 Boughner DR, Barnes HJM. The enigma of the risk of stroke in mitral valve prolapse. Stroke $1985 ; 16$ : 175-7.

160 Sandok BA, Giuliani ER. Cerebral ischemic events in patients with mitral valve prolapse. Stroke 1982; 13: 448-50.
161 Bergeron $G A$, Shah $P M$. Echocardiography unwarranted in patients with cerebral ischemic events. $\mathrm{N}$ Engl J Med 1981; 304: 489.

162 Smith DL, McKnight TE. TIAs, completed strokes and mitral valve prolapse. South Med J 1981; 74: 1454-6.

163 Come PC, Riley MF. Bivas NK. Roles of echocardiography and arrhythmia monitoring in the evaluation of patients with suspected systemic embolism. Ann Neurol 1983; 13: 527-31.

164 Nishide Ma, Irino T, Gotoh $M$ et al. Cardiac abnormalities in ischemic cerebrovascular disease studied by two-dimentional echocardiography. Stroke 1983; 14: $541-5$.

165 Reem JA, Hachinski VC, Boughmer DR, Barnell HJM. Value of cardiac monitoring and echocardiography in TIA and stroke patients. Stroke 1985; 16: 950-6.

166 Good DC, Frank S, Verhulst S, Sharma B. Cardiac abnormalities in stroke patients with negative arteriograms. Stroke 1986; 17: 6-11.

167 Kelley RE, Pina I, Lee $S$-C. Cerebral ischemia and mitral valve prolapse: case-control study of associated factors. Stroke 1988; 19: 443-6.

168 Wolf $P A$, Sila $C A$. Cerebral ischemia with mitral valve prolapse. Am Heart J 1987; 113: 1308-15.

169 Edmunds $\mathbf{L H}$. Thrombotic and bleeding complications of prosthetic heart valves. Ann Thorac Surg 1987; 44: 430-45.

170 Lieberman A, Hass WK, Pinto A et al. Intracranial hemorrhage and infarction in anticoagulated patients with prosthetic heart valves. Stroke 1978; 9: 18-24.

171 Edmunds $L H J r$. Thromboembolic complications of current cardiac valvular prostheses. Ann Thorac Sur 1982; 34: 96- 106.

172 Shattel LFB. The prevention of prosthetic valve thromboembolism. Uses and limilations of anti-platelet drugs. Int J Cardiol 1983; 3: 87-91.

173 Braunwald $E$. Valvular Heart Disease. In: Braundwald E (Ed.). Heart Disease. Philadelphia: W.B. Saunders, 1984; 1063

174 Coon WW, Willis $P W$. Hemorrhagic complications of anticoagulant therapy. Arch Intern Med 1974; 133 : 386-92.

175 Kase CS, Robinson RK, Stein RW et al. Anticoagulant related intracerebral hemorrhage. Neurology 1985; 35 : 943-8.

176 Katholi RE, Nolan SP, McGuire LB. Living with prosthetic heart valves: Subsequent noncardiac operations and the risk of thromboembolism or hemorrhage. Am Heart J 1976; 92: 162-7.

177 Katholi RE, Nolan SP, McGuire LB. The management of anticoagulation during noncardiac operations in patients with prosthetic heart valves. A prospective study. Am Heart J 1978; 96: 163-5. 
178 Bodnar $A G$, Hutter $A M J r$. Anticoagulation in valvular heart disease preoperatively and postoperatively. $I n$ : Conti CR (Ed.). Cardiac Drug Therapy, Cardiovascular Clinics 1984; 4: 247-64. Philadelphia: FA Davis Co.

179 Tinker JH, Tarhan S. Discontinuing anticoagulant therapy in surgical patients with cardiac valve prostheses: observations in 180 operations. JAMA 1978; 239: 738-9

180 Pruitl AA, Rubin RH, Karchmer AW, Duncan GW. Neurologic complications of bacterial endocarditis. Medicine 1978; 57: 329-43.

181 Hart RG, Kagan-Hallet K, Joerns SE. Mechanisms of intracranial hemorrhage in infective endocarditis. Stroke 1987; 18: 1048-56.

182 Davenport J, Hart RG. Prosthetic valve endocarditis 1976-1987. Antibiotics, anticoagulation, and stroke. Stroke 1990; 21: 993-9.

183 Heyen PT, Scholz DG, Edwards WP. Incidence and size of patent foramen ovale in the first ten decades of life. Mayo Clin Proc 1984; 59: 17-20.

184 Biller J, Adams HP. Johnson MR et al. Paradoxical cerebral embolism: eight cases. Neurology 1986; 36 : 1356-60.

185 Harvey $J R$, Teague SM, Anderson JL et al. Clinically silent patent foramen ovale with evidence of cerebral embolism. Ann Intern Med 1986; 105: 695-7.

186 Lechat $P$, Mas JL, Lascault $G$ et al. Prevalence of patent foramen ovale in patients with stroke. $N$ Engl J Med 1988; 318: 1148-52.

187 Colemnan SA, Wilson-MacDonald J. Fatal paradoxical thrombo-embolism during anaesthesia. Anaesthesia 1988; 43: 213-5.

188 Dalman $R$, Kohler $T R$. Cerebrovascular accident after Greenfield filter placement for paradoxical embolism. J Vasc Surg 1989; 9; 452-4.

189 Black S, Muzzi DA, Nishimura RA, Cucchiara RF Preoperative and intraoperative echocardiography to detect right-to-left shunt in patients undergoing neurosurgical procedures in the sitting position. Anesthesiology 1990; 72: 436-8

190 Shuiab A. Cerebral infarction and ventricular septal defect. Stroke 1989; 20: 957-8.

191 Keith D, Rose V, Collins G, Kidd BSL. Ventricular septal defect. Incidence, morbidity, mortality in various age groups. Br Heart J 1971; 33 (Supp): 81-7.

192 Bjerkelund $C J$, Orning $O M$. The efficacy of anticoagulant therapy in preventing embolism related to D.C. electrical conversion of atrial fibrillation. Am J Cardiol 1969; 23: 208-16.

193 Fisher M, Kase CS, Stelle B, Mills RM Jr. Ischemic stroke after cardiac pacemaker implantation in sick sinus syndrome. Stroke 1988; 19: 712-5.
194 Adams $D F$, Fraser $D B$, Abrams $H C$. The complication of coronary arteriography. Circulation 1973; 48: 609- 18.

195 Bourassa MG, Noble J. Complication rate of coronary arteriography. A review of 5250 cases studied by a percutaneous femoral technique. Circulation 1976; 53: 106-14.

196 Oliva A, Scherokman B. Two cases of occipital infarction following cardiac catheterization. Stroke 1988; 19: 773-5.

197 Dawson DM, Fischer EG. Neurologic complications of cardiac catheterization. Neurology 1977; 27: 496-7.

198 Sones FM Jr. Complications of coronary arteriography and left heart catheterization. Cleve Clin J Med 1978; 45: 21-3.

199 Lockwood K, Capraro J, Hanson M, Conomy J. Neurologic complications of cardiac catheterization. Neurology 1983; 33 (Suppl 2): 143.

200 Kent KM, Bentiusglio LG, Block PC el al. Percutaneous transluminal coronary angioplasty. Report from the Registry of the National Heart, Lung, and Blood Institute. Am J Cardiol 1982; 49: 2011-20.

201 Dorros G, Cowley MJ, Simpson J et al. Percutaneous transluminal coronary angioplasty: report of complications from the National Heart, Lung, and Blood Institute PTCA Registry. Circulation 1983; 67: 723-30.

202 Galbreath C, Salgado ED, Furlan AJ, Hollman J. Central nervous system complications of percutaneous transluminal coronary angioplasty. Stroke 1986; 17 616-9. 